\title{
TRILHA SENSITIVA COMO ESTRATÉGIA DE ENSINO DO BIOMA CERRADO
}

\author{
Claudia Zukeran Kanda ${ }^{1}$ \\ João Antônio da Costa Andrade ${ }^{1}$ \\ Carlos Augusto Moraes e Araújo ${ }^{1}$ \\ Paula Garcia Meirelles ${ }^{2}$
}

\begin{abstract}
Resumo: O Cerrado é reconhecido como a savana mais rica do mundo em biodiversidade, assim o seu estudo no ensino se reveste de grande importância no sentido de fortalecer a formação dos alunos para conhecer e praticar a preservação ambiental deste bioma. $O$ objetivo deste trabalho foi verificar 0 processo de aprendizagem sobre o bioma cerrado pela interação dos alunos em uma aula diferenciada, utilizando os cinco sentidos (tato, olfato, paladar, audição e visão). O método fundamenta-se fato de tentar reaproximar as pessoas da natureza temporariamente, despertando para o uso dos sentidos na exploração de "trilhas sensitivas". Os resultados demonstraram que o uso da trilha sensitiva mostrou-se satisfatório no aumento do interesse dos alunos e no desenvolvimento do aprendizado sobre o cerrado.
\end{abstract}

Palavras-chave: Educação Ambiental; Trilha Sensitiva. Ciências; EnsinoAprendizagem.

\section{Introdução}

\section{Cerrado}

Durante as décadas de 1970 e 1980 houve um rápido deslocamento da fronteira agrícola, que resultou em $67 \%$ de áreas do Cerrado "altamente modificadas", com voçorocas, assoreamento e envenenamento dos ecossistemas, restando, atualmente apenas $20 \%$ de área em estado conservado (BRASIL, [20--]; DURIGAN; FRANCO; SIQUEIRA, 2004). A relativa facilidade de desmatamento da sua vegetação permite a conversão rápida de extensas áreas naturais, fragmentando habitats e populações, bem como

\footnotetext{
${ }^{1}$ Universidade Estadual Paulista "Júlio de Mesquita Filho". E-mail: claudiakand@gmail.com.

${ }^{2}$ Fundação de Educacional de Andradina.
} 
colocando em ameaça de extinção diversas espécies de sua fauna e flora, principalmente as que dependem de grandes porções de habitats intactos e bem preservados. Obras que ocasionam grandes impactos ambientais diretos e indiretos, como usinas hidrelétricas, também contribuem para agravar esta realidade (SILVEIRA, 2004; JÁCOMO, 2004; SILVEIRA et al., 2009).

Pode-se falar da preservação da natureza como sendo algo vital para a humanidade, mas se o ser humano não perceber, entender e repensar suas relações com o meio ambiente, e dar outro sentido à importância que tem este tema em sua vida, sua compreensão sobre este fato será incompleta (MATAREZI, 2001). O distanciamento progressivo da sociedade em contato com a natureza impede esta percepção do ambiente enquanto parte indissociável do ser humano. Sendo assim, é indiscutível a importância do estudo sobre as questões ambientais em todos os níveis de escolarização. A inserção do assunto cerrado no processo de aprendizagem, além de fortalecer o conhecimento intrínseco desse bioma, pode despertar o interesse por temas ambientais correlatos.

\section{Aprendizagem pelos sentidos}

Como todo ser vivo interage com o mundo a sua volta por meio dos órgãos ou estruturas dos sentidos, pode-se construir um ambiente pedagógico através de experiências únicas, como por exemplo, atividades práticas e saídas de campo onde é preciso interagir com o meio e essa interação leva à reflexão e à busca de conhecimento, sendo também um jeito prazeroso de gerar conhecimento (MÖLLER; FISCHER, 2007).

$\mathrm{Na}$ disciplina de Ciências é de suma importância utilizar viagens de estudo como estratégia para aprendizagem. Mas infelizmente, nos deparamos com uma constante dificuldade em levar os alunos para uma aula em campo. Sendo assim, a trilha sensitiva é um método alternativo que pode ser aplicado no estudo de diversos biomas onde é possível reproduzir de maneira diferente o ambiente natural dentro das escolas, de modo que facilite a aprendizagem. Além disso, a proposta fundamenta-se no fato das pessoas deixarem de utilizar apenas o sentido da visão, despertando para o uso dos outros sentidos na exploração de Trilhas Interpretativas e "Perceptivas" (PASQUALETO; MELO, 2007; MATAREZI, 2001).

Numa sociedade que supervaloriza a visão e é dominada pelas imagens, deixa-se em segundo plano os outros sentidos. Os relatos sobre experimentos que suprimem temporariamente a visão indicam que essa experiência potencializa realmente os demais sentidos e que a vivência se torna única e marcante, havendo uma profunda reflexão das pessoas sobre as inter-relações entre sociedade e natureza no tempo e no espaço (MATAREZI et al., 2003 citado por PASQUALETO; MELO, 2007).

Portanto, é de fundamental importância o estímulo à percepção ambiental e seu estudo para que se possa entender melhor as relações do ser humano com o ambiente, levando assim ao processo de sensibilização, 
julgamento e conduta adequada. $\mathrm{O}$ objetivo deste trabalho foi verificar $\mathrm{O}$ processo de aprendizagem sobre o bioma cerrado dos alunos da $6^{a}$ série do ensino fundamental por meio de uma trilha sensitiva.

\section{Material e Métodos}

A trilha sensitiva foi apresentada aos alunos da 6a série do ensino fundamental da Escola Estadual Profa Léa Silva Moraes e Escola Estadual Arno Hausser, situadas no município de llha Solteira - SP. Para o desenvolvimento do projeto participaram seis alunos colaboradores do curso de Licenciatura em Ciências Biológicas da Unesp de Ilha Solteira. Ao todo, participaram oitenta e sete alunos e o projeto foi dividido em quatro etapas. Foram necessárias doze aulas de cinquenta minutos cada para desenvolver todo o projeto nas duas turmas da sexta série da Escola Arno Hausser e oito aulas, também de cinquenta minutos cada, para uma turma da sexta série na Escola Profa Léa Silva Moraes.

A primeira etapa consistiu na elaboração e aplicação de um questionário inicial (Figura 1) para analisar o conhecimento prévio dos alunos sobre o bioma cerrado. Na segunda etapa foi reproduzido dentro das escolas, um ambiente para simular o bioma cerrado. Em uma sala de aula escura, montou-se uma trilha dispondo vários materiais que compõem o bioma cerrado (Figura 2), além da inclusão de alguns elementos para representar a ação negativa do homem na natureza. Os materiais da flora, exceto os frutos, utilizados na trilha foram coletados no na Fazenda de Ensino, Pesquisa e Extensão da Unesp (FEPE) Selvíria/MS. Os frutos foram coletados na FEPE - Cerrado. O Centro de Conservação de Fauna Silvestre de Ilha Solteira - CESP emprestou, de seu acervo, as penas, os animais empalhados e os crânios.

Escola:__Nome:_ Série:

1- O que é serapilheira e qual a sua importância?

2- Cite algumas características típicas das plantas do cerrado e dê alguns exemplos de plantas encontradas no cerrado.

3- Qual a importância dos microorganismos existente no solo?

4- Quais são os prejuízos causados à fauna e a flora quando jogamos lixo em locais indevidos?

5- Qual a importância de alguns animais no restabelecimento da flora?

6- Sob o ponto de vista fisionômico o cerrado possui diversas formações ecossistêmicas. Quais são elas?

7- Porque alguns animais estão ameaçados de extinção? Cite alguns animais encontrados no bioma cerrado.

8- Você acha importante a presença da biodiversidade no cerrado? Por quê?

Figura 1: Questionário inicial utilizado para avaliar o conhecimento prévio dos alunos sobre o bioma cerrado.

Revbea, São Paulo, V. 9, № 1: 23-36, 2014.

revista brasileira

educação

ambiental 


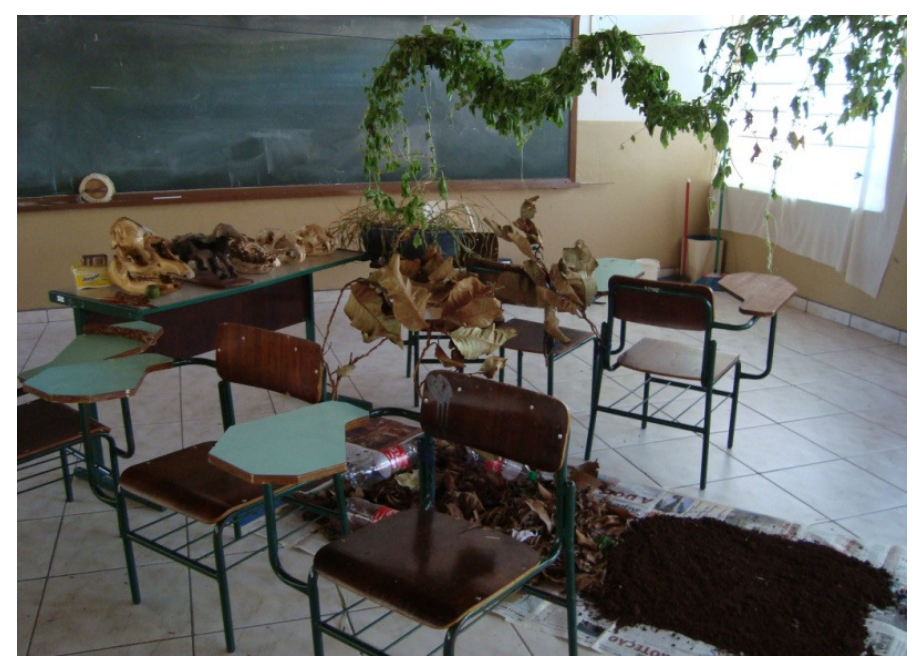

Figura 2: Reprodução do bioma dentro da sala de aula na Escola Estadual Profa Léa Silva Moraes.

As salas disponibilizadas pelas escolas para o desenvolvimento do projeto eram utilizadas para outras atividades escolares. Assim montou-se a trilha um pouco antes da dinâmica e esta era desmontadas ao término das aulas. Nesta sala, entravam quatro alunos vendados sendo auxiliados pelos monitores guia no decorrer do percurso na trilha, sendo que este indicava qual o sentido (tato, olfato, paladar e audição) deveria ser utilizado em cada objeto, mas não restringindo o uso de outro sentido pelo aluno. Vale ressaltar que a privação da visão se deu para despertar o interesse e curiosidade pelos alunos durante a trilha, conforme menciona Matarezi et al. (2003, apud PASQUALETO; MELO, 2007), sendo este sentido explorado após a dinâmica. Os alunos que participaram da trilha foram orientados a não comentar sobre o que havia dentro da sala com os colegas que ainda não haviam participado.

Enquanto alguns alunos participavam da trilha sensitiva, o restante participava da dinâmica Adivinhe quem eu sou? Nesta atividade, um aluno segurava uma foto de algum animal e tinha que descrever características para que os colegas adivinhassem qual era este animal. $O$ monitor auxiliava para que características como reino, o bioma a qual esta espécie pertence e características significativas da espécie fossem ditas pelo aluno descritor.

Os materiais colocados na trilha sensitiva e como foi o meio de exploração pelos alunos, estão descritos abaixo.

Serapilheira: a serapilheira foi disposta no chão durante o percurso da trilha. $O$ sentido utilizado foi o tato, onde os alunos caminharam sobre a serapilheira e agacharam para senti-lo com a mão. 
Solo: o solo foi disposto no chão durante o percurso da trilha. O sentido utilizado foi o tato, sendo que os alunos caminharam sobre o solo e agachavam para senti-lo com a mão.

Fitofisionomias e flores do cerrado: as fitofisionomias e flores (Caliandra sp, Caryocar brasiliense, Passiflora alata e Solanum lycocarpum) do cerrado foram exploradas através da visão, com fotos em slides mostrados durante a discussão, após a trilha sensitiva. Foram penduradas algumas trepadeiras durante o percurso da trilha para que os alunos tivessem a sensação que estavam entrando em um cerradão

Gramíneas: colocou-se um vaso contendo gramíneas para que fosse explorado com o tato.

Som das aves e penas: durante toda a permanência na sala de aula, foram reproduzidos os sons de várias aves típicas do cerrado (Aratinga aurea, Pitangus sulphuratus, Rupornis magnirostris e Turdus rufiventris) obtidas no site Aves do Brasil [20--] e as penas foram dadas nas mãos dos alunos vendados para que tentassem adivinhar o que era.

Animais empalhados e crânios: foram dispostos crânios e animais empalhados de espécies típicas de cerrado para que os alunos sentissem com as mãos. As espécies de cerrado foram escolhidas de modo que representassem os níveis tróficos (insetívoros, herbívoros e carnívoros).

Frutos do cerrado: as frutas frescas (Baru - Dypterix alata, Marmelo - Alibertia sp, Mangaba - Hancornia sp e Jurubeba - Solanum paniculatum) foram entregues na mão dos participantes para que eles pudessem sentir o aroma e forma. O pequi (Caryocar brasiliense) em conserva foi dado para que sentissem o aroma e degustassem.

Lixos: os lixos recicláveis foram colocados junto com o solo e a serapilheira para que durante a caminhada na trilha, os participantes se deparassem com estes materiais. Foram mostrados após a trilha, durante a discussão, slides com várias fotos de animais prejudicados pelo lixo e ambientes degradados pelo depósito inadequado do lixo.

Troncos de cerrado com galhos tortuosos e cascas espessas e, folhas grossas e ásperas: os ramos de folhas de lixeira (Curatella americana) delimitaram o percurso da trilha. As folhas, assim como os galhos foram explorados pelo tato.

$\mathrm{Na}$ terceira etapa do projeto houve um debate na sala de aula para que os alunos comentassem o que eles sentiram dentro da sala e foi explicada qual a relação deste material com o bioma cerrado, além de informações complementares como localização do bioma, clima, entre outras. Este debate teve como auxílio os materiais utilizados na trilha sensitiva, slides com figuras e vídeos elucidativos sobre o cerrado. Nesta fase também, os alunos tiveram que segurar representantes da cadeia alimentar (crânios, vaso com plantas e terra) em frente aos colegas e com o auxílio destes, tiveram que dispor a ordem correta da cadeia alimentar, ou seja, a terra representando os micro- 
organismos existentes no solo, o vaso com plantas, crânios de herbívoros e carnívoros. Mostrou-se também um painel confeccionado pelos alunos de licenciatura em Ciências Biológicas da Unesp de Ilha Solteira com alguns objetos colados, contendo a informação do tempo de decomposição.

Para a análise do desenvolvimento da aprendizagem, foi realizada uma avaliação em que os alunos responderam o mesmo questionário aplicado no início da atividade. Neste questionário final foi acrescentada uma pergunta para avaliar a opinião dos alunos sobre as aulas ministradas neste projeto. As respostas foram analisadas em forma de gráficos com as porcentagens de participação, acertos e erros, antes e depois da realização da trilha sensitiva e por escola. Realizou o Teste t para avaliar se existe diferença entre as fases antes e depois da realização da trilha sensitiva somente dos alunos que estavam presentes na aplicação dos questionários antes e após o tratamento. Também foram levantados os tipos de respostas e as respectivas porcentagens.

Visando satisfazer a curiosidade de alguns alunos, sanar as dúvidas ainda existentes e aumentar ainda mais o nível de aprendizado, uma revisão, contendo as respostas do questionário, foi distribuída no final do projeto.

\section{Resultados e discussão}

A série escolar foi escolhida com base nas experiências positivas dos autores Möller e Fischer (2007) no uso de práticas e sentidos sensoriais para o ensino de ciências. Estes autores ressaltam que é importante o estímulo pelos professores do uso dos movimentos corporais em todas as séries, principalmente antes dos 12 e 13 anos. O tema "Biomas brasileiros" está inserido na programação dos conteúdos da sexta série, mas ainda não tinha sido trabalhado em sala de aula, sendo assim cedidas as aulas de ciências para o desenvolvimento do projeto.

Após a participação do primeiro grupo de alunos na trilha sensitiva, percebeu-se que eles saíam entusiasmados para comentar com seus colegas o que sentiram dentro da sala de aula. Assim, em vez de os participantes voltarem para a brincadeira do "Adivinhe quem eu sou?", logo após a trilha, estes eram encaminhados para um grupo com um monitor para que comentassem o que sentiram. De acordo com Matarezi (2001), é através da reflexão em grupo que ocorre a construção coletiva de conhecimento, pois à medida que os relatos são feitos ao grande grupo ocorre um compartilhamento das descobertas e também há uma nova elaboração conceitual e perceptiva do processo vivenciado. Desta forma, percebeu-se que se a discussão fosse realizada logo após a dinâmica, poder-se-ia aproveitar a animação dos alunos e assim obter mais desenvolvimento na discussão e consequentemente no aprendizado. Isto não foi possível pela falta de disponibilidade de tempo oferecido pelas escolas, pois o projeto foi realizado no período das aulas de ciências. Também por isso houve pouco tempo para que os alunos interagissem com os objetos da trilha sensitiva. 
Como o trabalho foi realizado em uma época que não havia disponibilidade dos frutos in natura para o consumo, os alunos só puderam sentir o formato e o cheiro. Eles puderam apenas degustar o pequi em conserva por se tratar de uma fruta bastante comercializada e de fácil acesso na região. A maioria dos participantes não quis consumir o pequi de olhos vendados, pois ficaram receosos com o cheiro forte, mas alguns já conheciam a fruta e comentaram que consomem o pequi em suas casas.

Todos os alunos foram bastante participativos nas dinâmicas, explorando com diversos sentidos os objetos da trilha. Esta diversidade está relacionada com o relato de Cornel (1996, apud MATAREZI, 2001), de que quando somos impedidos de enxergar, somos forçados a recorrer a outros sentidos menos usados do que a visão. Com o som das aves, muitos perguntaram se não havia animais vivos ou perigosos dentro da sala. Dois alunos ficaram com medo e fizeram a trilha sem as vendas. Após a participação na trilha, alguns alunos quiseram participar de novo ou permanecer na sala para poder ver melhor os objetos e a participação dos colegas na trilha, até mesmo guiá-los. Além disso, alguns funcionários das escolas e alunos de outras séries também quiseram participar da trilha sensitiva.

Os questionários iniciais e finais com nenhuma resposta foram desconsiderados na análise do desenvolvimento do aprendizado. Os alunos da Escola Estadual Arno Hausser mostraram menor interesse em responder o questionário inicial e final, fato este observado durante a aplicação destes e pela quantidade de pessoas que entregaram as avaliações iniciais e finais em branco (respectivamente, 22,03\% e 23,40\%). Na Escola Estadual Prof ${ }^{\mathrm{a}}$ Léa Silva Moraes, $10,71 \%$ dos alunos não responderam o primeiro questionário, mas todos responderam o questionário final.

A incidência de respostas semelhantes não foram todas comentadas nas Figuras 3 a 10, mas percebeu-se que os alunos abordaram diversos temas em cada questão.

Notou-se que houve uma diferença significativa no aprendizado entre as escolas (Figura 1 a 8 ). Na escola em que os alunos se mostraram mais participativos e a incidência de indisciplina são menores, comparados a outra escola, houve um maior rendimento nos acertos e respostas incompletas e um menor número de questões não respondidas após o projeto. A porcentagem de erros é maior em relação aos acertos para as duas escolas na questão dois, pois em vez de citar características típicas das plantas do cerrado, muitos descreveram as fitofisionomias, conforme se pode observar na Figura 5. Esta confusão pode ter relação com o aumento de $11,35 \%$ de erro na questão seis pelos alunos da escola Arno Hauser após o projeto. Observou-se também que houve um aumento de erros após o projeto na questão 1 e na questão cinco os erros aumentaram $1,81 \%$ e $4,47 \%$, respectivamente, apenas na escola Arno Hauser. Outro fato a ser considerado é que os alunos da Arno Hauser arriscaram mais para responder o primeiro questionário e a Lea, mais o segundo. 


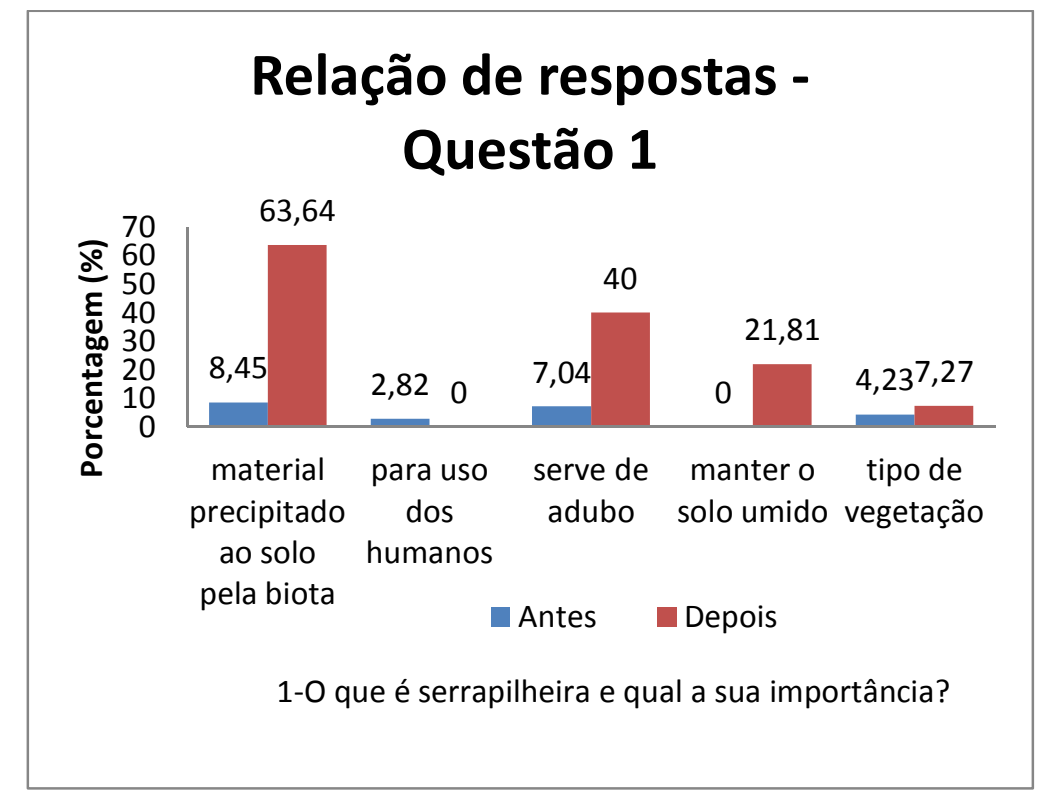

Figura 3: Tipos e porcentagem de respostas apresentadas pelos alunos, nos questionários inicial e final, a respeito da serrapilheira.

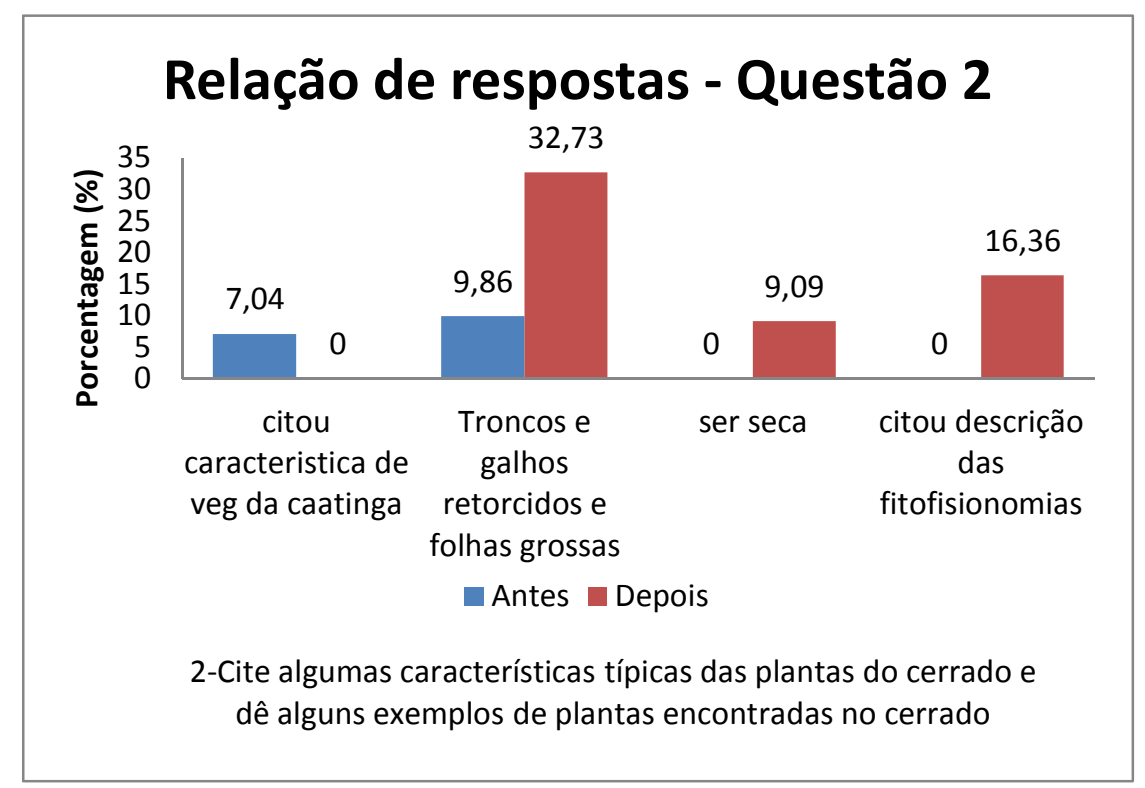

Figura 4: Tipos e porcentagem de respostas apresentadas pelos alunos, nos questionários inicial e final, a respeito das características típicas das plantas do cerrado. 


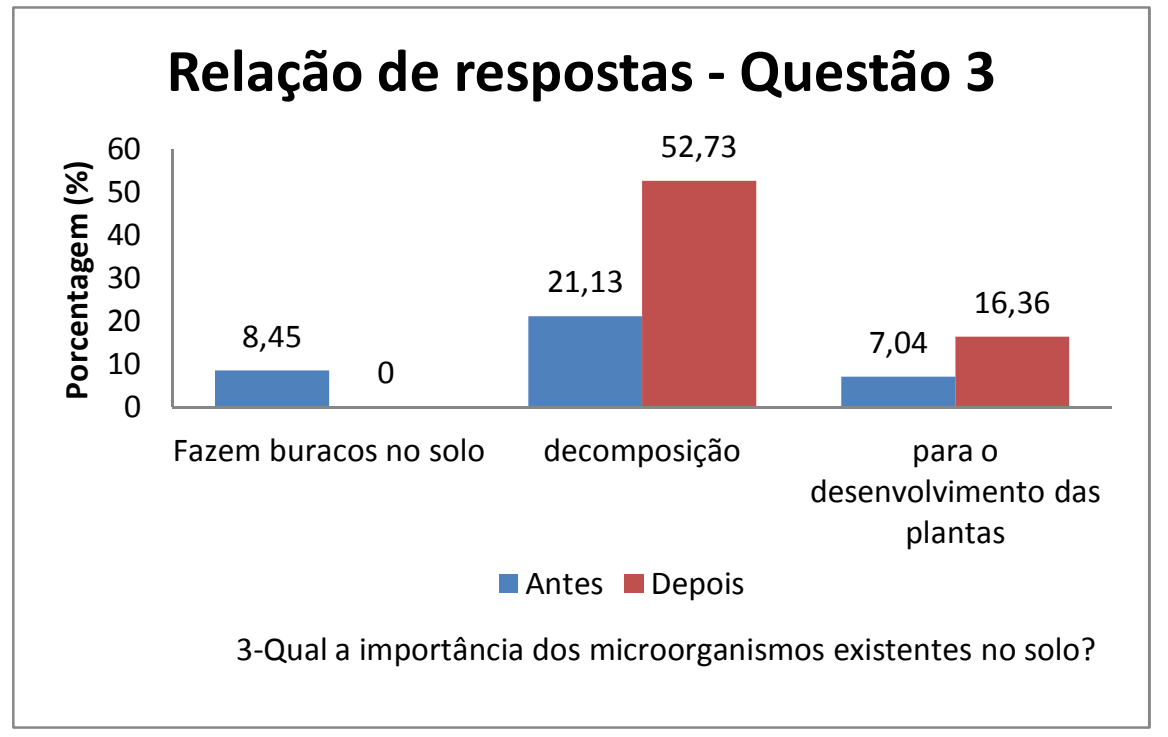

Figura 5: Tipos e porcentagem de respostas apresentadas pelos alunos, nos questionários inicial e final, a respeito da importância dos microrganismos existentes no solo.

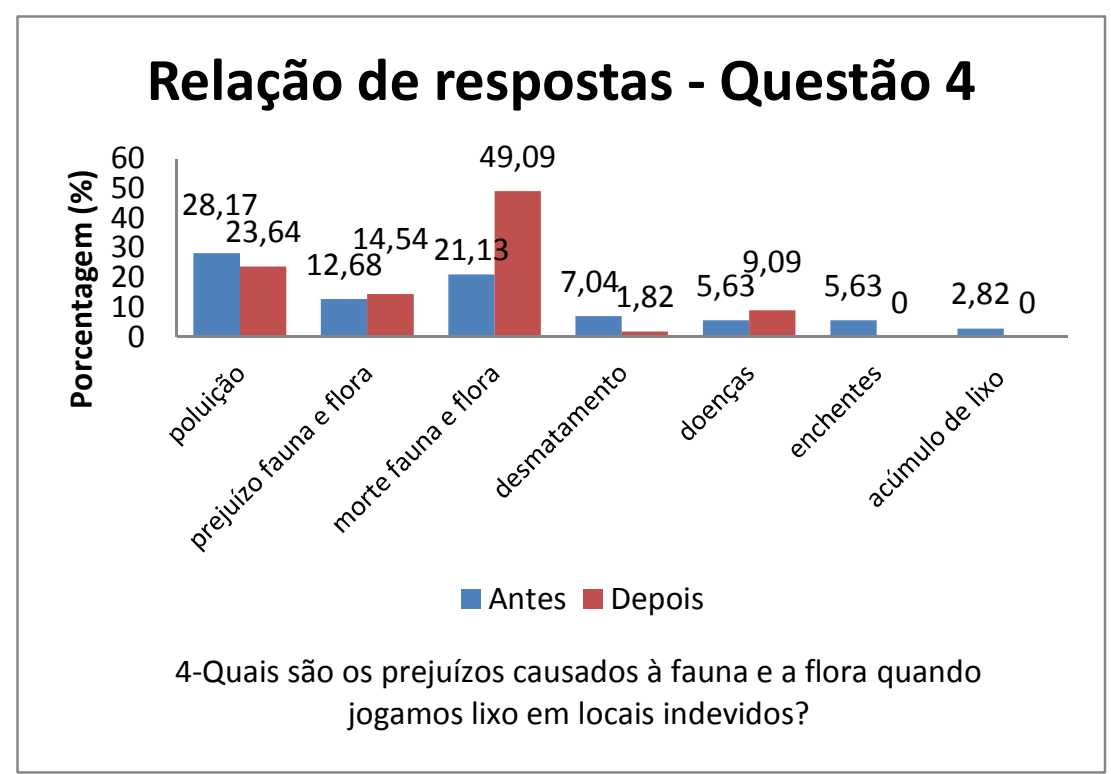

Figura 6: Tipos e porcentagem de respostas apresentadas pelos alunos, nos questionários inicial e final, a respeito dos lixos. 


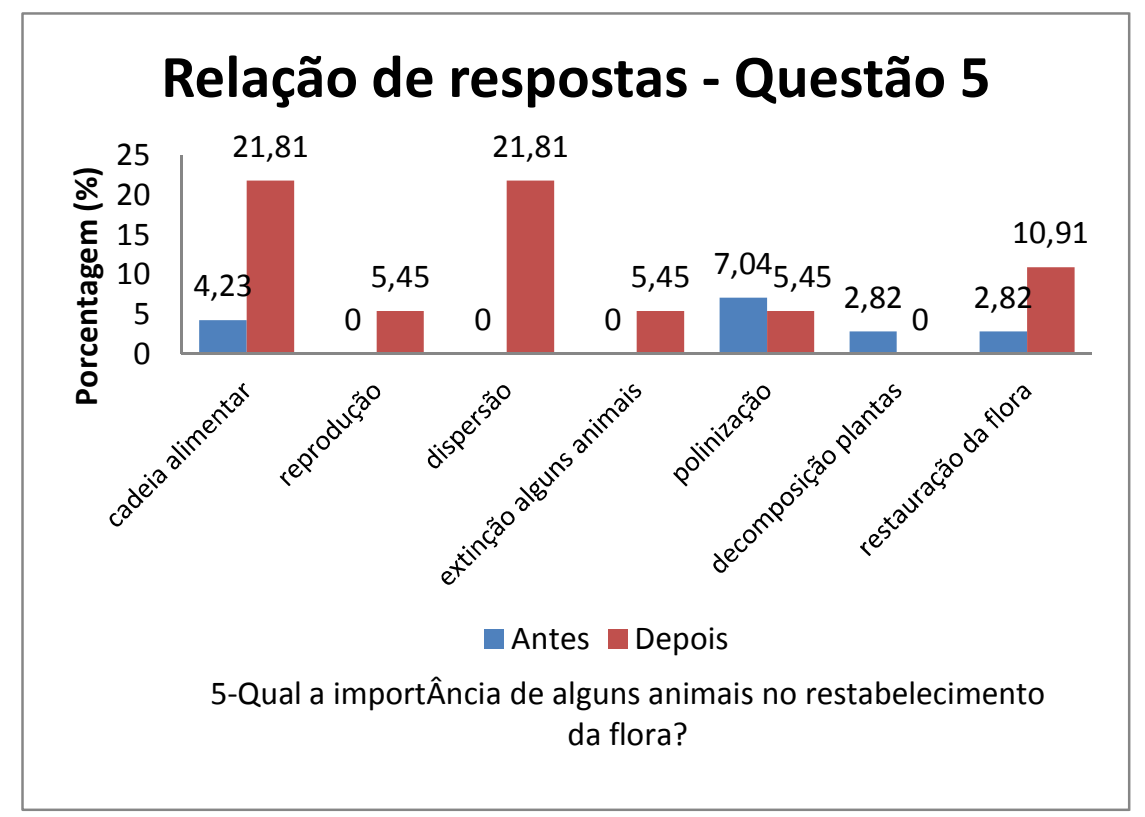

Figura 7: Tipos e porcentagem de respostas apresentadas pelos alunos, nos questionários inicial e final, a respeito da importância dos animais no restabelecimento da flora.

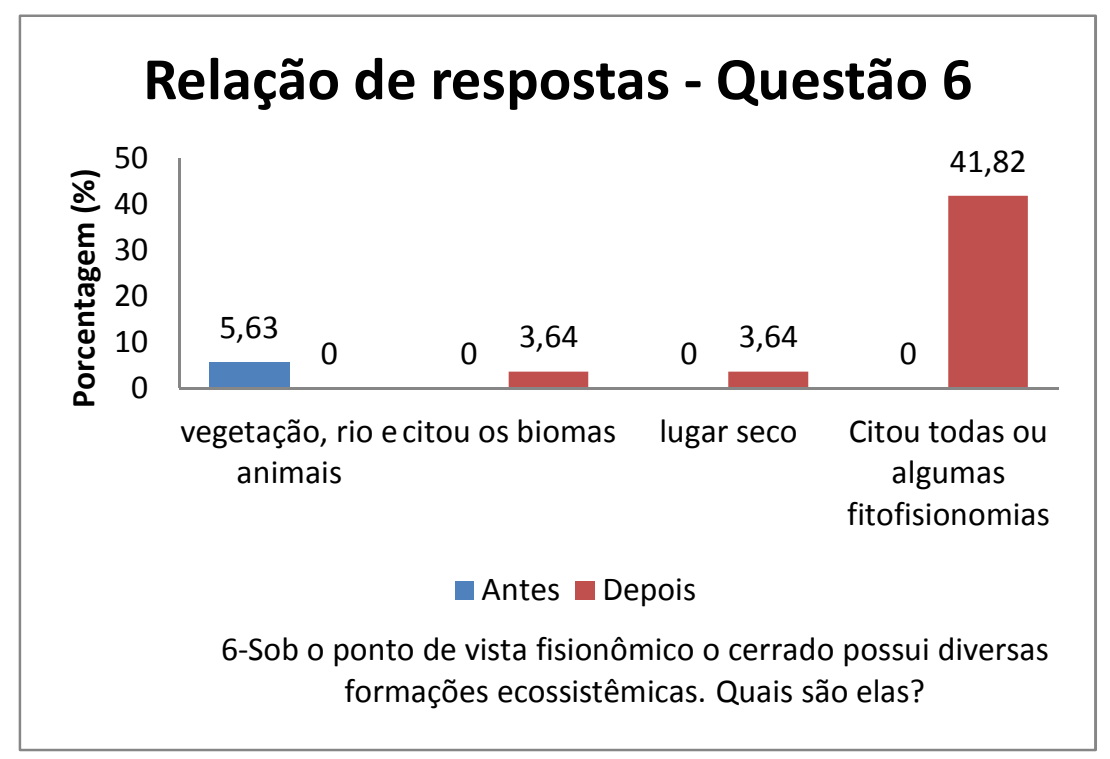

Figura 8: Tipos e porcentagem de respostas apresentadas pelos alunos, nos questionários inicial e final, a respeito das fitofisionomias do cerrado. 


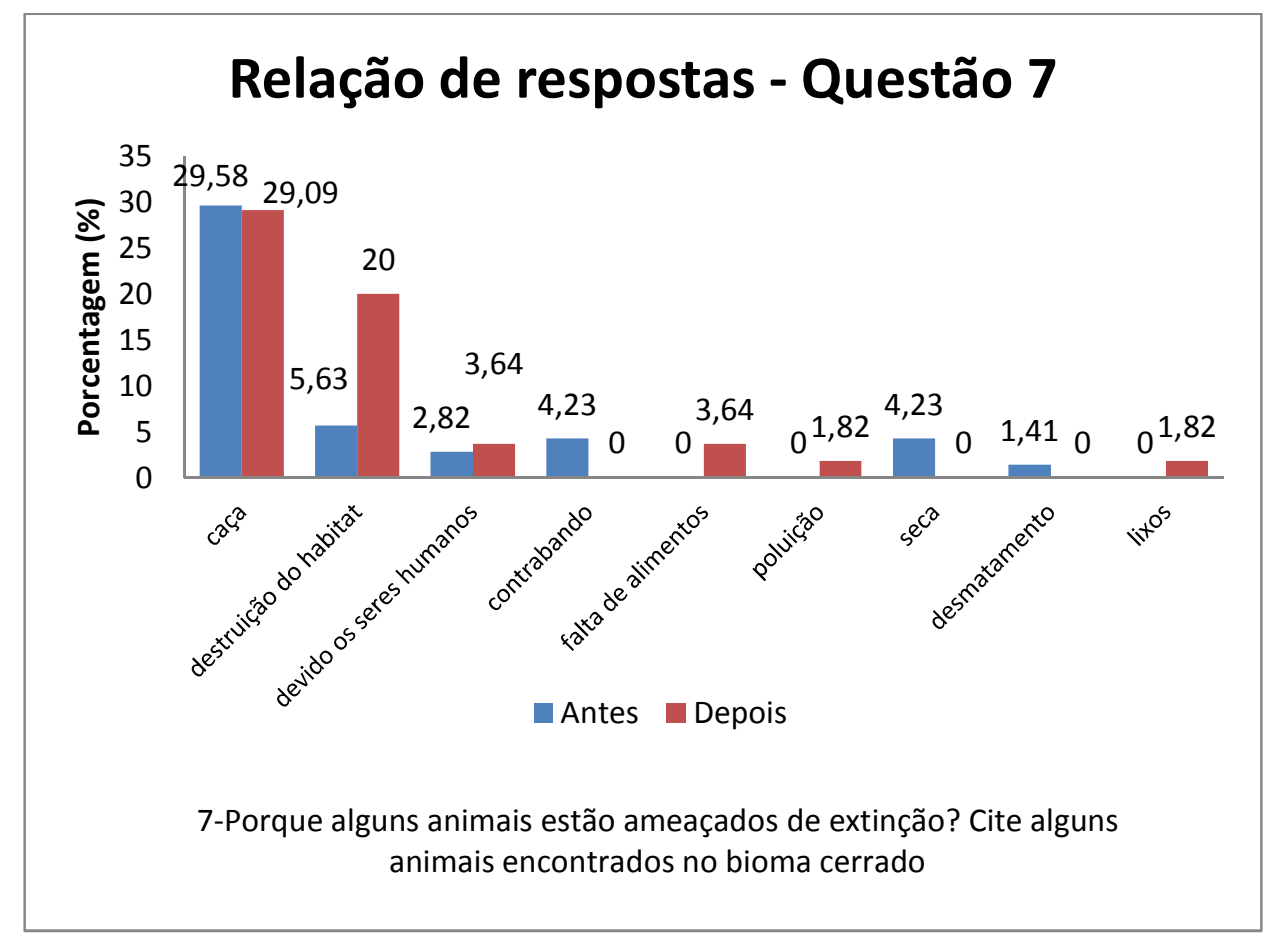

Figura 9: Tipos e porcentagem de respostas apresentadas pelos alunos, nos questionários inicial e final, a respeito da ameaça de extinção.

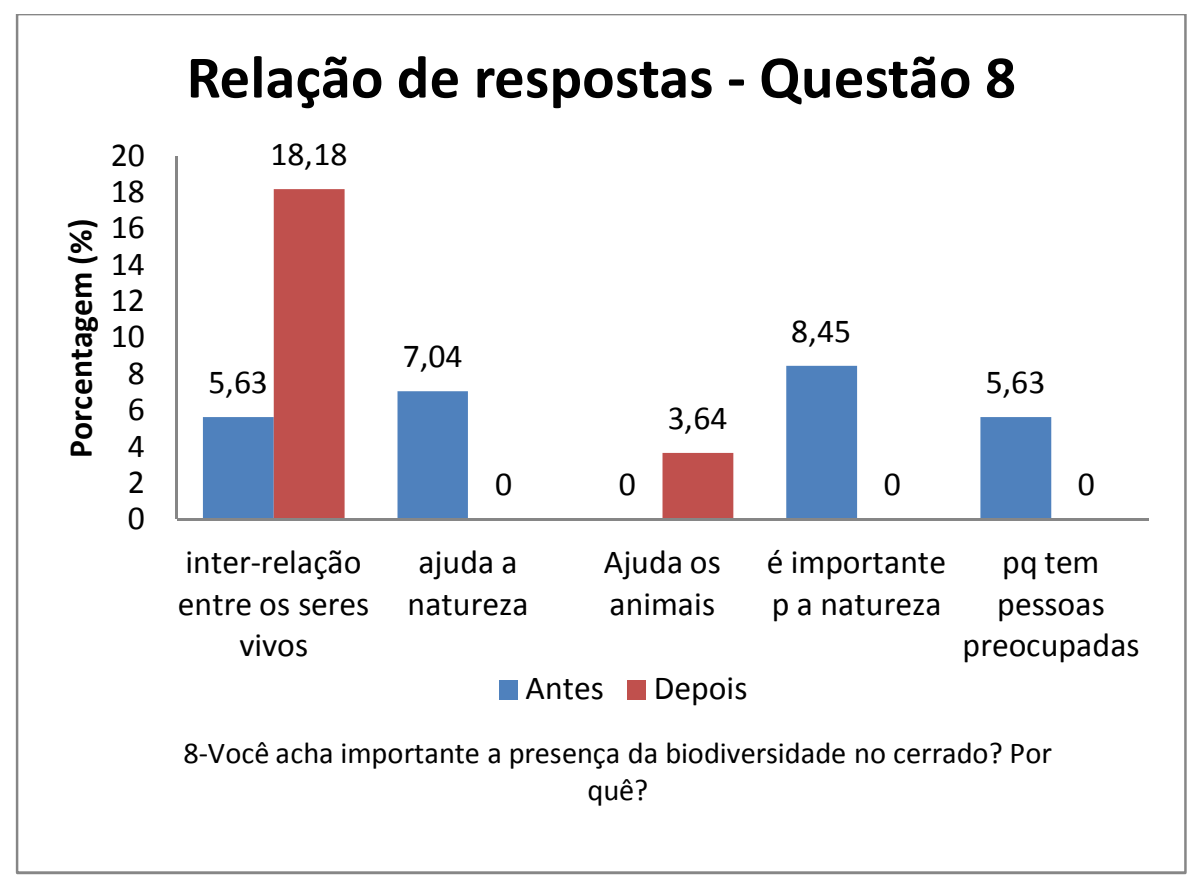

Figura 10: Tipos e porcentagem de respostas apresenadas pelos alunos, nos questionários inicial e final, a respeito da importância da biodiversidade.

Revbea, São Paulo, V. 9, Nº 1: 23-36, 2014. 
A análise geral indicou que o uso dos sentidos se mostrou satisfatório no desenvolvimento do aprendizado sobre o cerrado, conforme se pode observar na Tabela 1 e Figura 11. Após o projeto houve um aumento nas respostas certas em todas as questões e as corretas permaneceram com uma porcentagem maior em relação a outras respostas, exceto nas questões 2 e 6. Houve uma diferença significativa entre as respostas dos questionários aplicados antes e após o tratamento $(n=543$, variância de 0.035 antes e 0.23 depois da trilha, teste $\mathrm{t}=-15.182 \mathrm{p}=2.4 \mathrm{e}-47$ ). Embora, tenha ocorrido um post hoc do teste $\mathrm{t}$, podemos inferir que houve a experiência positiva descrita por Möller e Fisher (2007).

A análise dos questionários também indicou que os alunos entenderam os conceitos, mas a maioria não conseguiu formular uma frase correta e as respostas não foram concisas, evidenciando dificuldades de comunicação e expressão na forma escrita, reforçando assim, os dados de Ribeiro, Vóvio e Moura (2002) sobre a importância da preocupação com a qualidade do ensino no Brasil. Vale ressaltar que todos os alunos responderam no questionário final que ficaram satisfeitos com as aulas ministradas e que gostariam que aulas diferenciadas fossem realizadas nas escolas.

Tabela 1: Análise geral do desenvolvimento das respostas das questões de 1 a 9 antes e depois da trilha sensitiva.

\begin{tabular}{|c|c|c|c|c|c|}
\hline Questão & Fase & $\begin{array}{c}\text { Certo } \\
\text { (\%) }\end{array}$ & $\begin{array}{c}\text { Errado } \\
\text { (\%) }\end{array}$ & $\begin{array}{c}\text { Incompleto } \\
\text { (\%) }\end{array}$ & $\begin{array}{c}\text { Sem resposta } \\
\text { (\%) }\end{array}$ \\
\hline \multirow[t]{2}{*}{1} & Antes & 7,04 & 5,63 & 2,82 & 84,51 \\
\hline & Depois & 49,09 & 10,91 & 27,27 & 12,73 \\
\hline \multirow[t]{2}{*}{2} & Antes & 2,82 & 43,66 & 18,31 & 35,21 \\
\hline & Depois & 9,09 & 29,09 & 47,27 & 14,55 \\
\hline \multirow[t]{2}{*}{3} & Antes & 22,54 & 15,49 & - & 61,97 \\
\hline & Depois & 67,27 & 5,45 & - & 27,28 \\
\hline \multirow[t]{2}{*}{4} & Antes & 49,3 & 23,94 & - & 26,76 \\
\hline & Depois & 81,82 & 7,27 & - & 10,91 \\
\hline \multirow[t]{2}{*}{5} & Antes & 11,27 & 21,13 & - & 67,6 \\
\hline & Depois & 50,91 & 23,64 & - & 25,45 \\
\hline \multirow[t]{2}{*}{6} & Antes & - & 9,86 & - & 90,14 \\
\hline & Depois & 23,64 & 14,54 & 18,18 & 43,64 \\
\hline \multirow[t]{2}{*}{7} & Antes & 18,31 & 12,68 & 43,66 & 25,35 \\
\hline & Depois & 43,64 & 1,81 & 23,64 & 30,91 \\
\hline
\end{tabular}

Revbea, São Paulo, V. 9, N 1:23-36, 2014. 


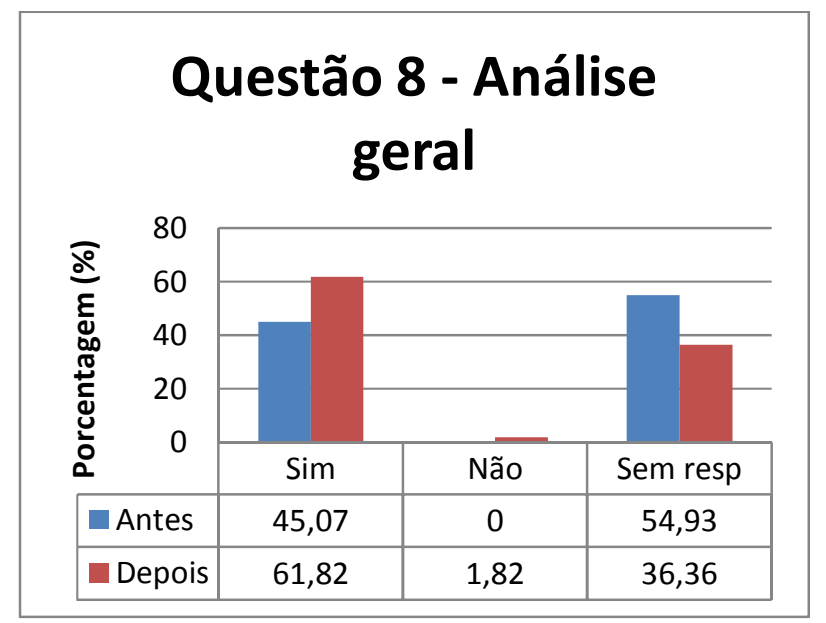

Figura 11: Análise geral do desenvolvimento das respostas dos questionários sobre a importância da biodiversidade antes e depois da trilha sensitiva.

\section{Conclusões}

A trilha sensitiva mostrou-se uma alternativa eficiente no processo de aprendizagem sobre o bioma cerrado, além de reaproximar as pessoas da natureza na tentativa de propiciar aos alunos uma sensibilidade à natureza, tornando-os mais conscientes da importância de preservação por meio de experiências diretas e mostrar que o homem tem influência direta e indireta na sua preservação.

O interesse demonstrado pelo tema evidenciou a importância do conhecimento e preservação do bioma Cerrado, sendo a introdução deste tema, como conteúdo nas escolas de ensino fundamental e médio, uma das primeiras providências no sentido de disseminar conhecimento e formar cidadãos preocupados com o assunto.

A adoção de novas metodologias de ensino que fujam do tradicionalismo, criando assim, oportunidades para que facilitem e potencializem a aprendizagem no ambiente escolar em todos as áreas do saber, deve ser incentivada.

\section{REFERÊNCIAS}

BRASIL. Instituto Brasileiro do Meio Ambiente e dos Recursos Naturais Renováveis. Ecossistemas brasileiros: cerrado. [20--]. Disponível em: $<$ http://www.ibama.gov.br/ecossistemas/cerrado.htm>. Acesso em: 02 out. 2008.

CORNEL, J. Brincar e Aprender com a Natureza: guia de atividades infantis para pais e monitores. Tradução: Maria Emilia de Oliveira. São Paulo: SENAC. Companhia Melhoramentos, 1996. 
DURIGAN, G.; FRANCO, G.A.D.C.; SIQUEIRA, M.F.A vegetação dos remanescentes de cerrado no Estado de São Paulo. In: BITENCOURT, M.D.; MENDONÇA, R.R. (Org.) Viabilidade de conservação dos remanescentes de cerrado no Estado de São Paulo. São Paulo: Annablume; FAPESP, 2004. p. 29-56.

JÁCOMO, A.T.A. Ecologia, manejo e conservação do queixada Tayassu pecari no Parque Nacional das Emas e em propriedades rurais em seu entorno. 2004. 120f. Tese (Doutorado em Biologia Animal) Universidade de Brasília, Distrito Federal, 2004.

MATAREZI, J. Trilha da vida: (re)descobrindo a natureza com os sentidos. Revista de Eletrônica do Mestrado em Educação Ambiental: Fundação Universidade do Rio Grande, v. 5/6, p. 55-67, 2000/2001.

MATAREZI, J. et al. Educação ambiental em unidades de conservação. Documento de mini curso realizado no II Simpósio Brasileiro de Engenharia Ambiental, Anais. Itajaí, 2003. CD-ROM.

MÖLLER, C.O.; FISCHER, J. A importância da prática, do lúdico e dos sentidos sensoriais humanos na aprendizagem da disciplina de Ciências de $5^{\underline{a}}$ a $8^{\underline{a}}$ série do Ensino Fundamental. Ação na aprendizagem. Revista de divulgação tecnocientífica do ICPG, v. 3, n. 11, p. 45-52, 2007.

PASQUALETO, A.; MELO, E.L. Trilha sensitiva no Memorial do Cerrado da Universidade Católica de Goiás. Revista Eletrônica do Mestrado em Educação Ambiental. v. 18, p. 1-11, 2007. Disponível em:< http://www.remea.furg.br/edicoes/vol18/art8v18a1.pdf >. Acesso em: 14 mar. 2009.

RIBEIRO, V.M.; VÓVIO, C.L.; MOURA, M.P. Letramento no Brasil: alguns resultados do indicador nacional de alfabetismo funcional. Educação e Sociedade, Campinas, v. 23, n. 81, p. 49-70, 2002.

SILVEIRA, L. Ecologia comparada e conservação da onça-pintada (Panthera onca) e onça-parda (Puma concolor), no Cerrado e Pantanal. 2004. 235f. Tese (Doutorado em Biologia Animal). Universidade de Brasília, Distrito Federal, 2004.

SILVEIRA, L. et al. Maned Wolf density in a Central Brazilian Grassland Reserve. Wildlife Management. v. 73, p. 68-71, 2009 